Original article

\title{
Assessing medical interns' attitude to general practitioner thesis $\&$ its performance challenges in Mazandran University of Medical Sciences
}

\author{
Fatemeh Salmeh$^{1}$, Mahbobeh Yaghobian",3,*, Vida Shafipour ${ }^{4}$
}

(Received: 13 April 2014; Accepted 3 June 2014)

\begin{abstract}
Background and Purpose: The thesis provides an opportunity for the students to conduct a study and thus to get ready for future research cases. Medical students have faced numerous challenges for their thesis including the selection of the subject, the study approval, equipment and supplies shortage and etc. We have conducted the present study to determine the attitude of medical interns towards the challenges they encounter when performing their thesis study in Mazandran Medial Sciences University in 2010.

Methods: This is a descriptive study on 96 medical interns of Medical School. Data were collected using a self-administered questionnaire about demographic characteristics, the students' status, thesis and their attitude towards challenges they encountered when conducting it.

Results: $40.6 \%$ of the medical interns in our study confirmed the necessity of thesis for general medicine program. The students ( $44.8 \%$ of the study units) agreed with the thesis being necessary for a general medicine program; it is best to offer it during the final 2-3 years of the program. The most important challenges were lengthy bureaucratic procedure and lack of organization among different levels of decision-making in order to approve the thesis. $34.4 \%$ of the students relatively believed that the supervising and consulting professors spend enough time on guiding and supervising the students.

Conclusions: It is necessary to reconsider the onset, the approval procedure, as well as the regular supervision of its progress.
\end{abstract}

Keywords: Thesis, Medical student, Attitude, Medical education, Challenge

\section{Introduction}

Completing a thesis marks the ultimate duty of a medical student in the general medicine program; it requires students to conduct a study in the field of medicine under the supervision of the supervising and consulting professors (1). Nowadays, the goal of medical education is to yield some graduates with critical thinking (2), an inquisitive and curious nature (3), as well as independent analysis and problem solving skills (4).

Thus, the purpose of a thesis requirement is to motivate medical students to achieve practical knowledge of the research method, the scientific report analysis, and answering potential for medical questions (5), as well as to improve their interest in researchbased medicine and furnish them with the ability to conduct in-depth studies in a specific field (6).

In order to complete a thesis, a student starts with planning for a scientific research (2), using databases and scientific articles to select his/her subject of interest, forming the study questions and

\footnotetext{
${ }^{1}$ Department of Public Health Nursing, Nasibeh Nursing \& Midwifery Faculty, Mazandran Medical Sciences University, Sari, Iran.

2,* Corresponding author: Department of Management Nursing, Nasibeh Nursing \& Midwifery Faculty, Mazandran Medical Sciences University, Sari, Iran. Email: yaghobian2005@yahoo.com.

${ }^{3}$ Traditional \& Complementary Medicine Research Centre. Mazandran Medical Sciences University, Sari, Iran.

${ }^{4}$ Department of Medical Surgical Nursing and Midwifery Faculty, Mazandran Medical Sciences University, Sari, Iran.
} 
hypotheses, determining the objectives and variables, and eventually submitting the study proposal to the respective faculty members of the department for discussion and approval (5).

Subsequently, the student obtains the consent of the study units for participation in the study, collects the required data, uses statistics to analyze the data and determine their significance, and is ultimately enabled to compose a well-structured scientific writing (3).

Improving the quality of education constitutes the cornerstone of an efficient medical education in which the graduates are not only able to pose correct questions, but also continuously search for the latest therapy options (4). Integrating a research activity in medical education will result in physicians who will benefit from evidence-based medicine and clinical trials and will be able to interpret and review scientific literature (4).

Such an educational approach will be indefinitely helpful throughout the professional life of a physician and leave a profound impact on their professional efficiency (7). Therefore, a thesis is considered an essential component of medical education (5). In addition, these theses may serve to resolve many national healthcare problems, and a large proportion of articles published result from the theses (3).

The conditions of thesis as an educational activity for students vary from nation to nation (8). For instance, the students in England are required to complete a dissertation in the magnitude of a large book but do so without professors' supervision. In Sweden, the students present their thesis only as an article. In other countries, such as Russia or Poland, the students will graduate after completing the general medicine program (9).

In the United States, a thesis is voluntary for most universities (10), whereas the educational systems of many countries, such as Germany, Spain, Finland, and India, require the completion of a medical thesis for graduation in a general medicine program $(9,4,11$, and 12).
Similarly, thesis is mandatory for medical students in Iran. In an English study, the medical students reported thesis to be an indispensable component of medical education and $88.1 \%$ considered it useful for them to compose a thesis (13). On the other hand, another English study in 2004 reported that writing a thesis is the main source of stress for the students (14). In another study, German students believed that the thesis delays graduation and prolongs the general medicine program (9).

Previous studies conducted in Iran suggest that there are many shortcomings and deficiencies in the medical thesis system. Despite the importance of medical thesis, most Iranian students often view it a source of discomfort ruining their happy memories of their final stage of education (15).

Numerous challenges await the students when working on their thesis: lack of infrastructures and facilities for completing a high-quality study, lack of knowledge to guide the students, statistics deficient knowledge (5), lack of a problem-solving approach, unreasonable demands to complete both research and internship duties simultaneously, and the stress behind completing the research (3).

These challenges have resulted in the current situation where many policymakers feel the compulsion to eliminate thesis from the general medicine program while many students wish to work on a thesis provided that the necessary amendments are made (3).

If medical education policymakers wish to preserve medical thesis as a medium to serve its purpose, it is necessary that they attempt to circumvent the challenges currently facing (5).

Assessing the medical students' attitude towards the procedure of completing a thesis will reveal the current strengths \& weaknesses to the policymakers and thus provide the ground for its revision, modification and improvement. We performed the present study to determine the attitude of medical interns towards the challenges they run into when conducting their thesis study in Mazandran Medial Sciences University in 2010. 


\section{Materials and Methods}

This is a descriptive study on the attitude of the medical interns in Medical School of at Mazandran Medical Sciences University in 2010. The study population consisted of all interns of Mazandran Medical Sciences University in 2010.

From February to September 2010, we used convenience sampling to recruit all male and female medical students who worked as interns in morning, evening and night shifts of healthcare centers and hospitals and were in the final stages of completing their medical thesis. Totally 96 students were selected as the study units.

The data collection tool was a self-administered questionnaire organized in 3 sections dealing with demographic characteristics, the thesis status and the interns' attitude towards their thesis and the challenges for completing it. To determine the questionnaire's face validity and content validity, the medical school faculty members' comments have been used and after conducting the pilot study on 15 intern students, it was approved; the reliability of the questionnaire was evaluated using $\alpha$-Cronbach; the reliability of the questionnaire was evaluated using $\alpha$-Cronbach $(\alpha=0.7)$. The questionnaires were handed out to the interns during their breaks or in the wards, and the responses were collected immediately.

In order to comply with the ethical considerations, we instructed the students not to mention their names or the names of their supervising professors; they were also informed that the findings will be reported to the deputy of education and deputy of research and technology of Mazandran Medical Sciences University.

In the attitude section, we offered 30 statements with a 5-point Likert scale ranging from 1 to 5 . The interns' attitude scores were classified as unfavorable (38 or less), slightly favorable (39-75), favorable (76-114), and very favorable (115-150).

Data were analyzed on SPSS 16 software. For this purpose, we used descriptive statistics (distribution of frequency) as well as Chi-square to compare the qualitative variables. The significance level was considered with $95 \%$ confidence interval.

\section{Results}

Our study interns consisted of $64.6 \%$ women and $35.4 \%$ men, with a mean age of $25 \mathrm{SD} \pm 2.012$ years. Classes of 2004 and 2001 had the highest and lowest number of interns in our study, respectively. The thesis type was descriptive in $38.5 \%$, experimental in $22.9 \%$, analytical in $21.9 \%$ and descriptive-analytical in $16.7 \%$ of cases.

The supervising professors were affiliates of the clinical departments in $80.2 \%$ and basic sciences departments in $19.8 \%$ of cases. The largest number of theses belonged to the department of internal medicine (22.9\%), followed by surgery (15.6\%), psychiatry (11.5\%), and pharmacology $(8.3 \%)$. The department of social medicine had the lowest number of the theses $(1.2 \%)$.

$40.6 \%$ of our study medical interns supported the necessity of thesis for general medicine program. $37.5 \%$ of the students relatively agreed that the theses are sufficiently qualified to be presented in international scientific journals. However, $29.2 \%$ of interns relatively agreed that the theses use unoriginal subjects and have low quality. Moreover, 37.5\% somewhat approved that medical thesis wastes the students' time. $44.8 \%$ of the study units completely complied with starting the thesis during the last 2-3 years of the medicine program.

Regarding the challenges of completing a thesis, $34.4 \%$ of the students relatively believed that the supervising and consulting professors spend enough time on guiding and supervising the students. Nevertheless, the lengthy bureaucratic procedure and lack of organization among different levels of decisionmaking in order to approve the thesis, poor access to professors of statistics for consultation, data statistical analysis, and pedantic emphasis of supervisors on minor details are completely supported. In addition, the challenges related to shortages of the equipment and supplies, subject selection, thesis approval in the respective department, scientific article preparation, 
and lack of appropriate access to internet were also reported with considerable frequency (Table 1).

Table 1. the medical interns' attitude towards challenges of completing a thesis for the general medicine program in Mazandran Medical Sciences University, 2010

\begin{tabular}{|c|c|c|c|c|c|}
\hline Stage & $\begin{array}{l}\text { Completely } \\
\text { Agree (\%) }\end{array}$ & $\begin{array}{l}\text { Relatively } \\
\text { Agree (\%) }\end{array}$ & $\begin{array}{l}\text { No } \\
\text { Opinion } \\
(\%)\end{array}$ & $\begin{array}{c}\text { Relatively } \\
\text { Disagree } \\
(\%)\end{array}$ & $\begin{array}{c}\text { Completely } \\
\text { Disagree } \\
(\%)\end{array}$ \\
\hline Lack of laboratory equipment and supplies & 26 & 22.9 & 25 & 12.5 & 13.5 \\
\hline $\begin{array}{l}\text { Easy use of international sources for } \\
\text { composing the proposal and final report }\end{array}$ & 13.5 & 28.1 & 13.5 & 29.2 & 15.6 \\
\hline $\begin{array}{l}\text { Lengthy bureaucratic procedure for thesis } \\
\text { approval }\end{array}$ & 59.4 & 26 & 5.2 & 7.3 & 1.2 \\
\hline $\begin{array}{l}\text { Lack of organization among different levels of } \\
\text { decision-making for thesis approval }\end{array}$ & 40.6 & 29.2 & 17.7 & 10.4 & 2.1 \\
\hline $\begin{array}{l}\text { Poor access to professors of statistics for } \\
\text { consultation }\end{array}$ & 39.5 & 31.3 & 11.5 & 11.5 & 6.3 \\
\hline Subject Selection & 19.8 & 31.3 & 19.8 & 21.9 & 7.3 \\
\hline Thesis approval in the respective department & 18.8 & 27.1 & 8.3 & 22.9 & 21.9 \\
\hline Scientific article preparation & 26 & 36.5 & 26 & 8.3 & 3.1 \\
\hline Appropriate access to internet & 12.5 & 26 & 9.4 & 19.8 & 32.3 \\
\hline Data statistical analysis & 35.4 & 29.2 & 24 & 7.3 & 4.2 \\
\hline $\begin{array}{l}\text { Pedantic emphasis on minor and unimportant } \\
\text { details }\end{array}$ & 58.3 & 24 & 11.5 & 3.1 & 3.1 \\
\hline
\end{tabular}

The findings of C-square test indicate the significant relationships between the clinical and basic sciences supervising professors and the students' opinions regarding lack of organization among different levels of decision-making for approving the thesis ( $\mathrm{p}=0.003$ ), (Table 2) as well as between the type of study and the students' opinions about lack of laboratory equipment and supplies for conducting the thesis $(\mathrm{p}=0.000)$ (Table 3).

Table 2. Relationship between supervising professors and students' opinion regarding lack of organization among different levels of decision-making for approving the thesis in the respective department

\begin{tabular}{lcccccc}
\hline Lack of organization & $\begin{array}{c}\text { Completely } \\
\text { Agree }\end{array}$ & $\begin{array}{c}\text { Relatively } \\
\text { Agree }\end{array}$ & $\begin{array}{c}\text { No } \\
\text { Opinion }\end{array}$ & $\begin{array}{c}\text { Relatively } \\
\text { Disagree }\end{array}$ & $\begin{array}{c}\text { Completely } \\
\text { Disagree }\end{array}$ & $\begin{array}{c}\text { Chi- } \\
\text { Square } \\
\text { Result }\end{array}$ \\
\hline Clinical professors & 35 & 21 & 11 & 10 & & $\mathrm{P}=0.003$ \\
Basic Sciences & 4 & 7 & 6 & 2 & & \\
\hline
\end{tabular}

Table 3. Relationship between the study type and the students' opinions regarding lack of laboratory equipment and supplies

\begin{tabular}{lcccccc}
\hline Lack of lab equipment & $\begin{array}{c}\text { Completely } \\
\text { Agree }\end{array}$ & $\begin{array}{c}\text { Relatively } \\
\text { Agree }\end{array}$ & $\begin{array}{c}\text { No } \\
\text { Opinion }\end{array}$ & $\begin{array}{c}\text { Relatively } \\
\text { Disagree }\end{array}$ & $\begin{array}{c}\text { Completely } \\
\text { Disagree }\end{array}$ & $\begin{array}{c}\text { Chi- } \\
\text { Square } \\
\text { Result }\end{array}$ \\
\hline Descriptive & 2 & 11 & 16 & 1 & 7 & \\
Analytical & 3 & 3 & 6 & 6 & 3 & $\mathrm{P}=0.000$ \\
Descriptive-Analytical & 9 & 5 & - & 2 & - & \\
Experimental & 11 & 3 & 2 & 3 & 3 & \\
\hline
\end{tabular}

\section{Discussion}

Medical research plays a key role for a country to get developed. Therefore, to participate as a student in a practical thesis project will pave the suitable ground for deciding about future clinical research cases. Based on our findings, the type of thesis was descriptive for most of the students in our studies. This is similar to the previous studies (4) whereas a study conducted in Arak Medical Sciences University in 2001 reported the majority of theses as descriptive cross-sectional studies (16).

In our study, the supervising professors were mostly the university-affiliated clinicians similar to the other studies reporting clinicians as the largest group of supervisors $(4,15)$.

Most subjects selected were affiliated to the major departments of internal medicine, surgery and psychiatry, respectively. This seems rational considering the fact that the students take a large number of theoretical and practical courses in these departments and are consequently better familiar with their professors. On the other hand, a study by Refahi et al (2003) reported the largest number of theses being conducted in the minor departments (17).

The majority of the medical students in our study concurred relatively with the necessity of medical thesis for general medicine program. In the Norwegian research by Hunskar et al (2009), most students agreed with the medical thesis (6) whereas in the study by Refahi et al (2003), the majority of study units conformed to the elimination of thesis from the educational system (17).

Our findings indicate that most students agree relatively with the fact that the theses have the potential to be presented in national and international journals and seminars consistent with the findings of the previous studies (17). The scientific merits of a thesis may be inferred from its acceptance in international scientific societies and publication in journals. However, many study units stated that they have difficulty preparing the manuscript for an article. Composing a scientific report requires specific skills 
and competency, and a student may only be expected to prepare the initial draft; it is then the responsibility of the supervising professor to apply the necessary changes and modifications. A study in Germany (1998), where thesis is required to be graduated from the medical school, reported that $66 \%$ of the students had published papers in Medline database. Another study in Stanford University reported $90 \%$ of the students to have participated in a voluntary research over a year, with $75 \%$ of them publishing at least one paper and $52 \%$ presenting a lecture in a national seminar (10). Similarly, Norwegian medical students were reportedly able to publish papers, present professional lectures in national and international conferences, and make international contacts regarding their field of study following the completion of their thesis (6).

The present study findings suggest that the majority of the students believed that the supervising and consulting professors spent sufficient time on guiding them during their work on the theses. Nonetheless, numerous studies observed that lack of continuous supervision by professors is the cause of many problems when working on a thesis $(9,5,3,11,18$, and 19).

The majority of the interns completely consented with starting to work on a thesis during the final 2-3 years of medicine program. The concurrence of internship with research will compromise clinical skills due to getting involved in the thesis procedure. Moreover, as the students often lack enough time to develop their thesis according to the proposed plan; their satisfaction with thesis will decrease considerably. A German study reported the mean time from onset to completion of a thesis as 4 years, and the mean time for executive procedures as 1 year (1).

Poor access to statistics professors for consultation and weakness in data analysis is a major challenge reported in our study, similar to the previous studies drawn findings $(1,17$, and 9). Currently, the course of statistics is instructed to the medical students during their clerkship; this course, however, is far from practicality and this brings about the fact that medical students are unable to perform statistical analysis of their data. In order to improve their skills, one solution may be to require medical students to select certain subjects in a number of fields and conduct a small-scale research under the professors' supervision. According to Mehta (2007), many supervising professors in medical schools are unaware of statistics as a science (20). Therefore, it is also necessary to educate faculty members in order to enable them to guide their students regarding data analysis.

A notable challenge mentioned in our study is the lack of laboratory equipment and supplies for conducting a research. Kabra \& Verma (2007) reported lack of appropriate infrastructure and equipment as a major challenge hindering the theses development (5). Currently, many teaching hospitals and healthcare centers do not have research laboratories and this is particularly problematic for students who are working on interventional studies or clinical trials. Thus, the need for research centers and laboratories is felt strongly. Supervising professors in each department have to assess the shortcomings and the required equipment for each thesis subject and strive to resolve them. Lack of proper internet access is another struggle stated by the students. Nowadays, internet has become the most important source of information and scientific articles; unless it is readily accessible, the introduction and discussion sections of thesis will suffer from lack of information.

\section{Conclusion}

The present study findings denote that the medical students in Mazandran Medical Sciences University generally agree with the need for medical thesis despite numerous challenges they run into when working on their theses, which of course require expert assessments for resolution and improvement. Considering the fact that composing a thesis is an important learning opportunity for students, it is possible to resolve the current challenges with efforts in order to achieve the research products of greater scientific value.

We sincerely recommend the supervising and 
consulting professors to conduct regular and periodic evaluation of the thesis project throughout the procedure since this helps to control and regulate the activities and resolves many challenges the students face. Furthermore, the modifications made in this way will render the study more useful and practical. Certain subjects in the "Statistics and Research Method" course, such as its importance, research methodologies and critical evaluation of scientific articles, must be instructed during the early years of general medicine program; in the subsequent years, research workshops, working with SPSS software, and practical activities must be considered for medical students. In addition, increasing the number of faculty members in the medical statistics department will improve the students' access to them. The supervising professors in medical schools must be required to participate in workshops dealing with conducting \& supervising the thesis with an emphasis on the practical issues. It seems that starting the thesis during the early years of clinical education will create more time for the students and thus relieve their stress. Faculty members in different departments may prepare a list of the proposed topics to the department manager in order to develop a subject bank complying with the research priorities defined by the ministry and local authorities; in this way, each department will be responsible for suggesting the prioritized subjects of research to the students who wish to start a thesis. In order to encourage young researchers, it is appropriate to adopt a motivational mechanism to select the top theses each year and grant rewards to them.

\section{Conflict of interests}

The author(s) declare that they have no competing interests.

\section{Authors' Contribution}

F.Salmeh did the study conception and design, statistical expertise, analysis and interpretation of data and supervision. M.Yaghobian did manuscript preparation, data collection and administrative support. V.Shafipour read and approved the final manuscript.

\section{Acknowledgments}

Thanks to all of the medical students who participated in this study. This article was extracted from Proposal number 33-88 accepted by Mazandaran University of Medical Sciences, Sari, Iran.

\section{References}

1. Changiz T, Adibi p, Hossieni M, Tootoonchi M. Supervisors viewpoints about the problems in the process of dissertations for general medicine program; Isfahan University of Medical Sciences. Iranian Journal of Medical Education. 2003; 3(9): 24-32.

2. Quitadamo Ian J, Kurtz M J. Learning to Improve: using writing to increase critical thinking performance in general education biology. CBE life Sci Educ. 2007; 6(2): 140-154.

3. Chaturvedi VN. Thesis as a part of MS/MD training program _where do we stand? Indian J Otolaryngol Head Neck Surg. 1998; 50(1): 7-10.

4. Nieminen P, Sipila K, Takkinen HM, Renko M, Risteli L. Medical theses as part of the scientific training in basic medical and dental education: experiences from Finland. BMC Med Educ. 2007; 7(51): 2-7.

5. Kabra SK, Verma IC. Thesis during MD: must or bust. Indian Journal of pediatrics. 2007; 74(9): 868-869.

6. Hunskaar S, Breivik J, Siebke M, Tømmerås $\mathrm{K}$, Figenschau K, Hansen JB. Evaluation of the medical student research program in Norwegian medical schools. A survey of student and supervisors. BMC Med Educ. 2009; 9(1): 43-50.

7. Guelich JM, Singer BH, Castro MC, Rosenberg LE. A gender gap in the next generation of physicianscientist: medical student interest and participation in research. J Investig Med. 2002; 50(6): 412-418.

8. Stellman JM, Cohen S, Rosenfiled A. Evaluation of one-year masters of public health program for medical students between their third and fourth years. Acad Med. 2008; 83(4): 365-370. PMID: 18367897.

9. Dewey M. Student's evaluation of research during 
medical studies: medical dissertation in Germany. Med Educ. 2003, 37(3): 278-280.

10. Cursiefen C, Altunbas A. Contribution of medical student research to the Medline-indexed publications of a German medical faculty. Med Educ. 1998; 32(4): 439-440.

11. Singhi S, Rajagopal R, Ludhiana RM, Nirmalan $P$, Hydari A, Ravikiran. PG thesis: idealistic VS realistic. Indian Journal of pediatrics. 2007; 74(9): 864-866.

12. Dhaliwal U, Singh N, Bhatia A. Masters theses from a university medical college: publication in indexed scientific journals. Indian J Ophtalmol. 2010; 58(2): 101-104. PMID: 20195030.

13. Kargar Gahromi S. Research project investigating the structure and principles of scientific writing in general $\mathrm{PhD}$ thesis, Kerman University of Medical Sciences during 1382-1372. Kerman: Kerman University of Medical Sciences; 2006.

14. Moffat KJ, McConnachie A, Ross S, Morrison JM. First year medical student stress and coping in a problem- based learning medical curriculum. Med Educ. 2004; 38(5): 482-491. PMID: 15107082.

15. Rezaeian M, Salem Z, Dehghan S, Sayadi Anari A, Iranmanesh F, Ahmad MH. Critical appraisal of submitted theses by medical students of Rafsanjan
Medical School during 1993- 2003. Journal of Rafsanjan University of Medical Sciences. 2009; 7(4): 217-226.

16. Davami MH, Moiini L, Rafiei M . Evaluation of principles considerations in the dissertations of medical students submitted at Arak University of Medical Sciences from 1373 (1994) to 1379 (2000). Arak Medical University Journal (AMUJ). 2001; 4(3): 23-31.

17. Refahi M, Refahi A. Quality of the thesis and its implementation: a survey of medical interns, Isfahan University of Medical Sciences August 1379. Research In Medical Sciences. 2000; 6(1): 1-6. http://fa.journals. sid.ir/ViewPaper.aspx?ID=97538.

18. Nolan M T, Wenzel J, Han HR, Allen JK, Paez KA, Mock V. Advancing a program of research within nursing faculty role. J Prof Nurs. 2008; 24(6): 364-370. PMID: 19022210.

19. Kabiru CW, Izugbara CO, Wambugu SW, Ezeh AC. Capacity development for health research in Africa: experiences managing the African doctoral dissertation research fellowship program. Health Res policy sys. 2010; 8(1): 21-26.

20. Mehta R. PG thesis: idealistic VS realistic. Indian J pediatr. 2007; 74(9): 865-866. PMID: 17901680. 